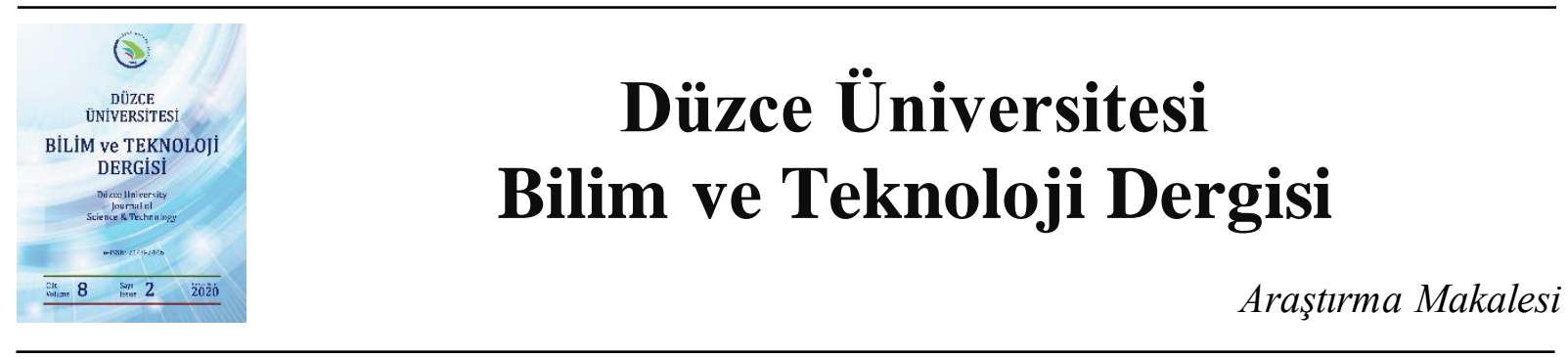

\section{Ofset Bükme Kalıplarında Bükme Açısı Konumunun Geri Esnemeye Olan Etkisinin Sonlu Elemanlar Yöntemi ile Analizi}

\author{
Vedat TAŞDEMİR ${ }^{\text {a,* }}$ \\ ${ }^{a}$ Makine ve Metal Teknolojileri Bölümü, Elbistan Meslek Yüksekokulu, Kahramanmaraş İstiklal Üniversitesi, \\ Kahramanmaraş, TÜRKIYYE \\ * Sorumlu yazarın e-posta adresi: vedat.tasdemir@istiklal.edu.tr \\ DOI: $10.29130 /$ dubited.684468
}

\begin{abstract}
ÖZET
Bu çalışmada, üzerine çok az çalışma bulunan bükme kalıplanndan biri olan ofset bükme işlemi sonlu elemanlar yöntemi (SEY) kullanılarak simule edilmiştir. Son zamanlarda, ofset bükme işlemi hem işlem adım sayısını a zaltmak hem de ima la tsüresini kısa ltmak için giderek yaygınlaşan biryöntem olmaya başlamıştır. Simüla syonda $90^{\circ}$ 'lik iki bükme açısına sahip kalıplar kullanılmıştır. Bükme deneyleri 3 farklı açısal konuma (yatay $0^{\circ}-90^{\circ}$, yukarı doğru kıvrımlı $45^{\circ}-45^{\circ}$ ve yukarı doğru kıvrımlı $30^{\circ}-60^{\circ}$ ) sahip ka lıplar kullanıla rak ya pılmıştır. Ça lışmada, kalıp açısı konumlarının geri esnemeye olan etkileri tespit edilmeye çalışılmıştır. Analizler sonucunda ileri esnemenin (nega tif geri esneme) oluştuğu ve en iyi sonucun $45^{\circ}-45^{\circ}$ konuma sa hip bükme kalıpla rında elde edildiği belirlenmiştir. Ayrıca, en düşük ölçü ve geometri tamlığının yatay bükme kalıbında olduğu ortaya çıkmıştır.
\end{abstract}

Anahtar Kelimeler: Bükme, Ofset bükme, Geri esneme, İleri esneme, Sonlu elemanlaryöntemi

\section{Analysis of The Effect of The Bending Angle Position on Springback in Offset Bending Dies by Using Finite Element Method}

\begin{abstract}
In this study, offset bending, one of the bending dies with very little work on it, was simulated using the finite element method (FEM). Recently, offset bending has become a widespread method of reducing both the num ber of process steps and the manufacturing time. In the simulations, dies with two bending angles of $90^{\circ}$ were used. The bending tests were carried out using dies having 3 different angular positions (horizontal $0^{\circ}-90^{\circ}$, upsweep $45^{\circ}-45^{\circ}$ and upsweep $30^{\circ}-60^{\circ}$ ). In the study, the effects of die angle positions on springback were tried to be determined. As a result of the analysis, it was determined that springgo (negative spring-back) occurs and the best result is obtained in bending dies with $45^{\circ}-45^{\circ}$ position. Also, the lowest dimension and geometry accuracy occurred in the horizontal bending die.
\end{abstract}

Keywords: Bending, Offset bending, Springback, Springgo, Finite element method 


\section{GiRis}

Bükme, imalat sektöründe yaygın olarak kullanılan sac metal şekillendirme yöntemlerinden biridir [1]. Bükme basit bir işlemi olmasına rağmen, geri esneme, zımba yükü ve gerilmiş yüzeylerde çatlak oluşumu gibi çeşitli sorunlara neden olabilir [2]. Hangi tür metal bükme yönteminin kullanılacağna karar verirken iş parçasının malzemesi, boyutu ve kalınlığı önemlidir. Ayrıca, bükme boyutu, bükme açısı, bükmeradyüsüvb. faktörler de dikkatealınmalıdır. En yaygın kullanılan bükme yöntemleri, döner kalıpla bükme, havabükme, kanal bükme, L, U ve V bükme, ofset (Z) bükmedir. Ofsetbükmeaynı anda iki $90^{\circ}$ 'lik bükme işleminin gerçekleştirilmesi işlemidir. Ofset bükme işlemi, tek bir $90^{\circ}$ 'lik bükme işleminden daha fazla kuvvet gerektirir.

Geri esneme, metal şekillendirmedeki temel kusurlardan biridir ve malzemenin elastik doğasından kaynaklanır. Geri esneme parçaların nihai şekli ile kalıpta şekillendirildikten sonraki şekli arasındaki fark olarak ölçülür. Sac malzeme şekillendirme işleminde malzeme üzerinden yükün kaldırılması neticesinde, elastik geri dönüşten dolayı meydana gelen geri ve ileri esneme, çıan ürünlerin geometri kalitesini, parça birim maliyetini vb. olumsuz yönde etkilemekte hatta ciddi şekil hatalarına sebep olabilmektedir [3, 4]. Bükme işleminde geri esneme miktarı malzemenin mekanik özelliklerine, bükme yarıçapına, zımba kalıp boşluğuna, kalınlığına, bükme açısına, ortam sıcaklığına ve baskı esnasında zımbanın kalıpta bekleme süresi gibi etkenlere bağlıdır [5]. Şekil 1'de bükme sonrası geri ve ileri esneme olayının şematik gösterimi görülmektedir.

Yapılan bükme çalışmaları incelendiğinde birçok araştırmacı, V, L, U bükme işlemi üzerine malzeme ve bükme işlem parametrelerinin etkilerini hem deneysel hem de sonlu elemanlar analizi yöntemini kullanarak araştırmışlardır [6-11]. Ancak yapılan araştırmalar neticesinde ofset bükme üzerine çok az sayıda çalışmaya rastlanmıştır. Thipprakmas ve Rojananan, of set $Z$ bükme işleminde geri esneme karakteristikleri ve bükme mekanizmasının analizi üzerine deneysel ve sonlu elemanlar metodunu kullanarak bir çalışma yapmışlardır. Çalışmalarında bükme açısının geri/ileri esnemeye olan etkilerinin araştırmışlardır. Çalışmalarının neticesinde ofset $Z$ bükme olayında dengesiz gerilme dağılımının etkisi sebebi ile her iki taraftaki geri esneme olayının da eşit olmadığını belirtmişlerdir [12]. Yine başka bir çalışmalarında, $Z$ bükme işlemine deney parametrelerinin etkisini istatistiki olarak araştırmışlardır. Deneylerde, iş parçası boyu ve genişliği, bükme açısı, kalıp radyüsü ve malzeme kalınlığı parametrelerinin kullanarak yaptıkları analizlerde, malzeme kalınlığının geri esnemede en etkili parametre olduğunu, daha sonra ise bükme açısı ve kalıp radyüsünün bunu takip ettiğinin belirtmişlerdir [13]. Güler, ofset bükme işleminde şekillendirme hızı ve malzeme etkisinin üzerine sayısal bir çalışma yapmıştır. Çalışma neticesinde, farklı malzeme ve hız seçiminin bükme sonrası malzemede oluşan maksimum Von Mises gerilmesi, maksimum incelme, şekillendirilebilirlik ve eğim açısı üzerine önemli

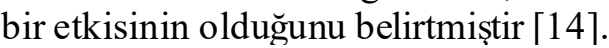

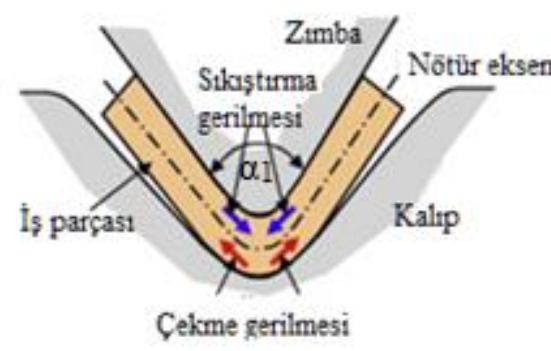

(a)

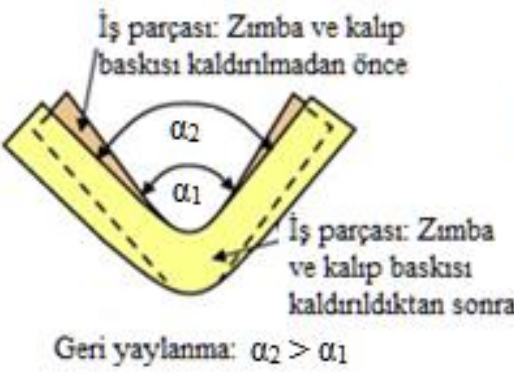

(b)

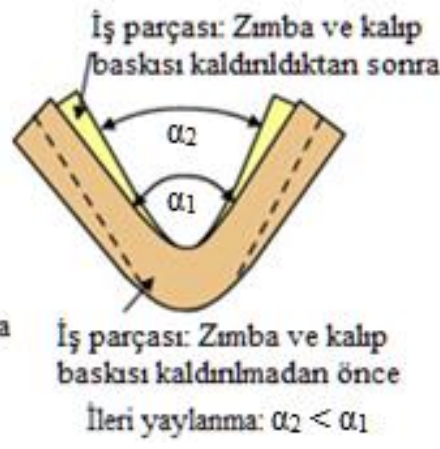

(c)

Şekil 1. Bükme işlemi ve sonrasındaki geri ve ileri esneme olayının şematikgösterimi [15]

Ofset bükme üzerine oldukça az çalışmanın olduğu tespit edilmiştir. Özellikle endüstriyel olarak da kullanılan kalıp açısı konumunun etkisi üzerine hiçbir çalışma yapılmamıştır. Bu açıdan bu çalışmanın özgün bir niteliğe sahip olduğu ve bilimsel açıdan önemli bir katkı sağlayacağı düşünülmektedir. Bu 
çalışmada, ofset $\mathrm{Z}$ bükme işlemi sonrası oluşan esnemeye kalıp konumunun etkisi sonlu elemanlar yöntemi kullanılarak araştırılmıştır.

\section{SONLU ELEMANLAR ANALIZI}

Sonlu elemanlar yöntemi (SEY), en iyi deney parametrelerini belirlemek amacı ile etkili bir yöntem olarak yaygın bir şekilde birçok alanda kullanılmaktadır. Bu çalışmada da üç farklı bükme açısı konumuna sahip ofset $Z$ bükme işlemi sonlu elemanlar yöntemi kullanılarak araştırıldı. Zımba ve kalıp rijit, iş parçası ise elestoplastik olarak tanımlanmıştır. Analizler, Simufact.forming programından yararlanılarak iki boyutlu olarak gerçekleştirildi. Analizlerde kullanılan parametreler Tablo 1'de, kalıp seti ve bükme sonrası oluşan açılar Şekil 2'de ve ofset Z bükme kalıp açısı konumları ise Şekil 3'de verilmiştir. Malzeme olarak analiz programının kütüphanesinden $2 \mathrm{~mm}$ kalınlığında soğuk şekillendirmeye uygun sıcak haddelenmiş yüksek akma dayanımına sahip 355MC (DIN1 .0976) çelik malzeme kullanılmıştır.

Tablo 1. Sonlu elemanlar simülasyon koşulları

\begin{tabular}{lll}
\hline Parametre & Özellik ve değer & Birim \\
\hline Malzeme & S355MC & \\
Simülasyon modeli & 2D düzlemsel simetrik model & \\
& İş parçası: Elestoplastik & \\
& Kalı/Zımba: Rijit & \\
Eleman boyutu ve tipi & $0,34($ kaba); Quads(dörtgen) $)$ & $\mathrm{mm}$ \\
Malzeme kalınlı̆ı (t) & 2 & $\mathrm{~mm}$ \\
Zımba ve kalıp kavisi & $\mathrm{R}_{\mathrm{z}}=2, \mathrm{R}_{\mathrm{k}}=2$ & $\mathrm{~mm}$ \\
Zımba hızı(V) & 100 & $\mathrm{~mm} / \mathrm{s}$ \\
Sürtünmekatsayısı $(\mu)$ & 0,1 & \\
Akma dayanımı $\left(\mathrm{R}_{\mathrm{e}}\right)$ & 422 & $\mathrm{MPa}$ \\
Poison oranı & 0,283 & \\
Yoğunluk & 7855,0 & $\mathrm{~kg} / \mathrm{m}^{3}$ \\
Ofset değeri(wı) & 12,5 & $\mathrm{~mm}$ \\
Bükme açısı $(\theta)$ & $90^{\circ}$ & \\
Bükme açısı konumu & Yatay, $45^{\circ}-45^{\circ}, 30^{\circ}-60^{\circ}$ & \\
İs parçası uzunluğu ve genişliği & 50 ve 20 & $\mathrm{~mm}$ \\
\hline
\end{tabular}
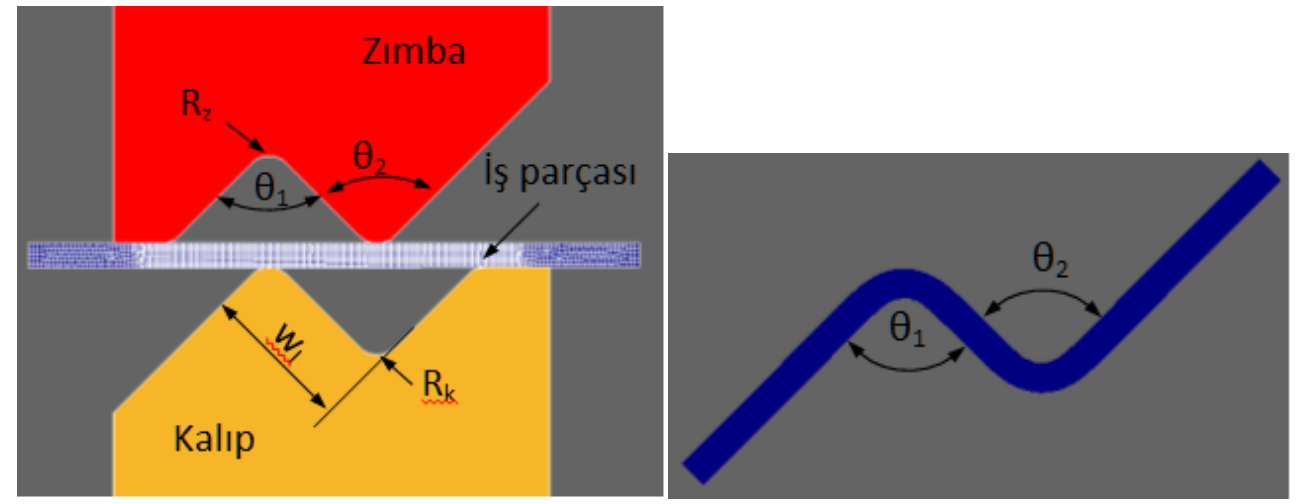

Şekil 2. Kalıp seti ve bükme sonrası oluşan bükme açıları 

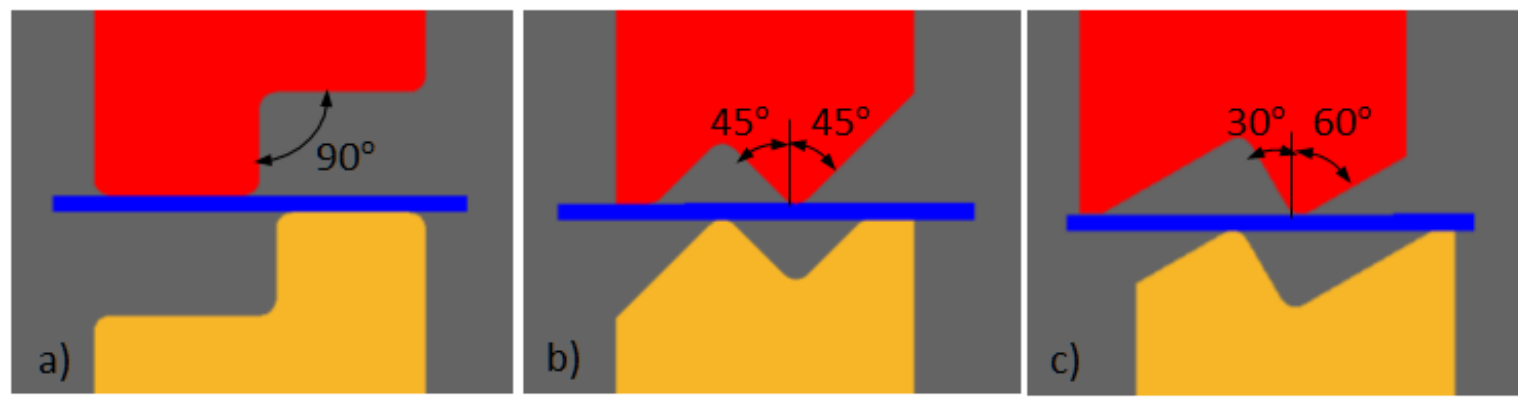

Şekil 3. Analizlerde kullanılan ofset bükme kalıp konumları a) Yatayb) $45^{\circ}-45^{\circ}$ c) $30^{\circ}-60^{\circ}$

\section{SONUCLAR VE TARTISMA}

Şekil 4, Şekil 5 ve Şekil 6'da zımba hareketine bağlı olarak bükerek şekillendirilen malzemede oluşan gerilme dağılımları görülmektedir.

Şekiller incelendiğinde zımba kurs boyu arttıç̧a bükme bölgesindeki gerilme de artmaktadır. Tüm şekillerde (c)'de görüldüğü gibi kurs boyu \% 100'e ulaştı̆̆ında gerilme en yüksek değere erişir. Burada en yüksek gerilme bükme bölgelerinde olmakla birlikte ofset bölgesinde de çekme veya baskı sonucu oluşmaktadır. Ancak kurs tamamlanıp kalıpların iş parçası ile olan teması ortadan kalktığında tüm şekillerde (d)'de görüldüğü üzere hem bükme hem de of set bölgesindeki gerilme telafi edilerek (geri dönerek) azalmaktadır. İşlem tamamlandıktan sonra en büyük gerilmeler; yatay, $45^{\circ}-45^{\circ}$ ve $30^{\circ}-60^{\circ}$ konuma sahip kalıplarda sırası ile $675,78 \mathrm{MPa}, 664,60 \mathrm{MPa}$ ve $683,38 \mathrm{MPa}$ olarak elde edilmiştir.

Bükme sonrası oluşan gerilme dağılımı ele alınarak Şekil 4, 5 ve 6 karşıllaştırıldığında, $45^{\circ}-45^{\circ}$ ve $30^{\circ}$ $60^{\circ}$ yukarı kıvrımlı konuma sahip kalıplarla elde edilen analizlerde gerilmenin (d), kama etkisi nedeni ile bükme bölgelerinde (A ve B) toplandığı, ofset bölgesinde (C) ise daha dengeli olduğu görülmektedir. Yatay bükme kalıplarında ise ofset bölgesine yakın bükme bölgelerinde daha fazla yığılma olmuştur. En büyük gerilmenin tüm kalıp konumları için hembükme (B alanı) hem de ters bükmenin gerçekleştĭg (A alanı) bölgelerde sıkıştırma sonrası iç tarafta oluştuğu görülmektedir. Ayrıca tüm bükme işlemleri için hem of set bölgelerindeki hem de bükme bölgelerindeki gerilmeler dengeli değildir. Bu durum bir taraftaki $\mathrm{V}$ şeklin diğer taraftakini etkilemesi sonucu malzeme akışı ve gerilme dağılımındaki dengesizlikten kaynaklanmaktadır [12].

Yine analizlerden elde edilen sonuçlara göre bükülen numunelerden ölçü tamlığı(hassasiyet) ve bükme kalitesi en düşük olan yatay konuma sahip kalıplarla elde edilen bükmedir. Yatay kalıpla elde edilen analizde ofset bölgesindeki (C alanı) kusur açık bir şeklide görülmektedir. Bu durum yatay konuma sahip kalıplarla elde edilen parçanın ofset bölgesine bir baskı kuvvetinin etki etmemesinden kaynaklanmaktadır. Bu bölge ciddi bir çekme gerilmesine maruz kaldığından şekil bozukluğu oluşmaktadır. Yapılan ölçümler neticesinde tek taraflı yaklaşık $0,26 \mathrm{~mm}(\% 13)$ toplamda ise 0,52 mm'lik bir hata oluşmuştur. Diğer kalıp konumlarında ise bu bölgeye bask1 geldiği için böyle bir hata gözlenmemiştir.

Şekillendirme işlemi tamamlanıp kalıp baskıları kaldırıldığında malzemede geri veya ileri esneme olayı meydana gelir. Esnemeaçısından şekiller ele alınıp değerlendirildiğinde ise analizler sonucunda yapılan ölçümlerden yatay, $45^{\circ}-45^{\circ}$ ve $30^{\circ}-60^{\circ}$ konuma sahip kalıpların tamamında ileri esneme (IE) olay 1 olduğu belirlenmiştir. Şekil 7'de şekillendirme sonrası oluşan esneme açıları verilmiştir. Şekil incelendiğinde en büyük esneme $30^{\circ}-60^{\circ}$ konumunda, en küçük esneme ise $45^{\circ}-45^{\circ}$ konumunda çıkmıştır. En büyük esnemenin $30^{\circ}-60^{\circ}$ konumundaçıkmasının nedenin konumaçısından dolayı $30 \mathrm{o}$ 'lik tarafa etki edin kuvvet ile $60^{\circ}$ 'lik tarafa etki eden kuvvetin farklı olmasından kaynaklandığ düşünülmektedir. Yine tüm kalıplar için her iki V şekil tarafındaki bükme sonrası oluşan açı değerleri de birbirinden farklıdır. Bu durumun da nedeninin bir taraftaki $\mathrm{V}$ şeklin diğer taraftakini etkilemesi 
sonucu malzeme akışı ve gerilmedeki farklılıktan kaynaklandığı söylenebilir. Bükme işlemi sonrası oluşan en büyük geri esneme değerleri; yatay, $45^{\circ}-45^{\circ}$ ve $30^{\circ}-60^{\circ}$ konuma sahip kalıplarda sirası ile $1,19^{\circ}, 0,19^{\circ}$ ve $1,45^{\circ}$ dir. Geri esneme açısından en iyi sonuç $45^{\circ}-45^{\circ}$ konuma sahip kalıpta elde edilmiştir.

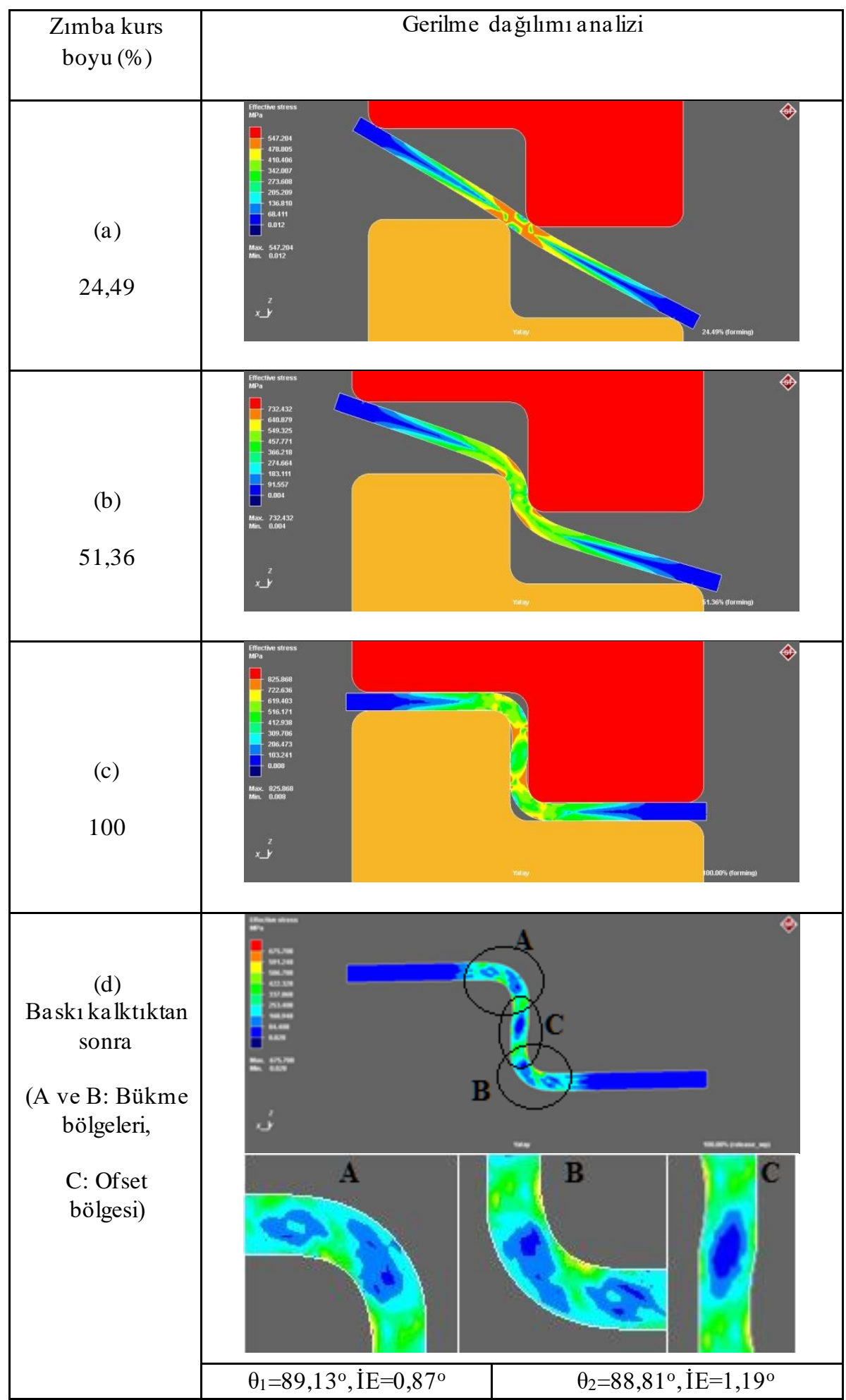

Şekil 4. Yatay $\left(0^{\circ}-90^{\circ}\right)$ kalıpla bükme esnasında ve sonrasında oluşan gerilme dağılımı 


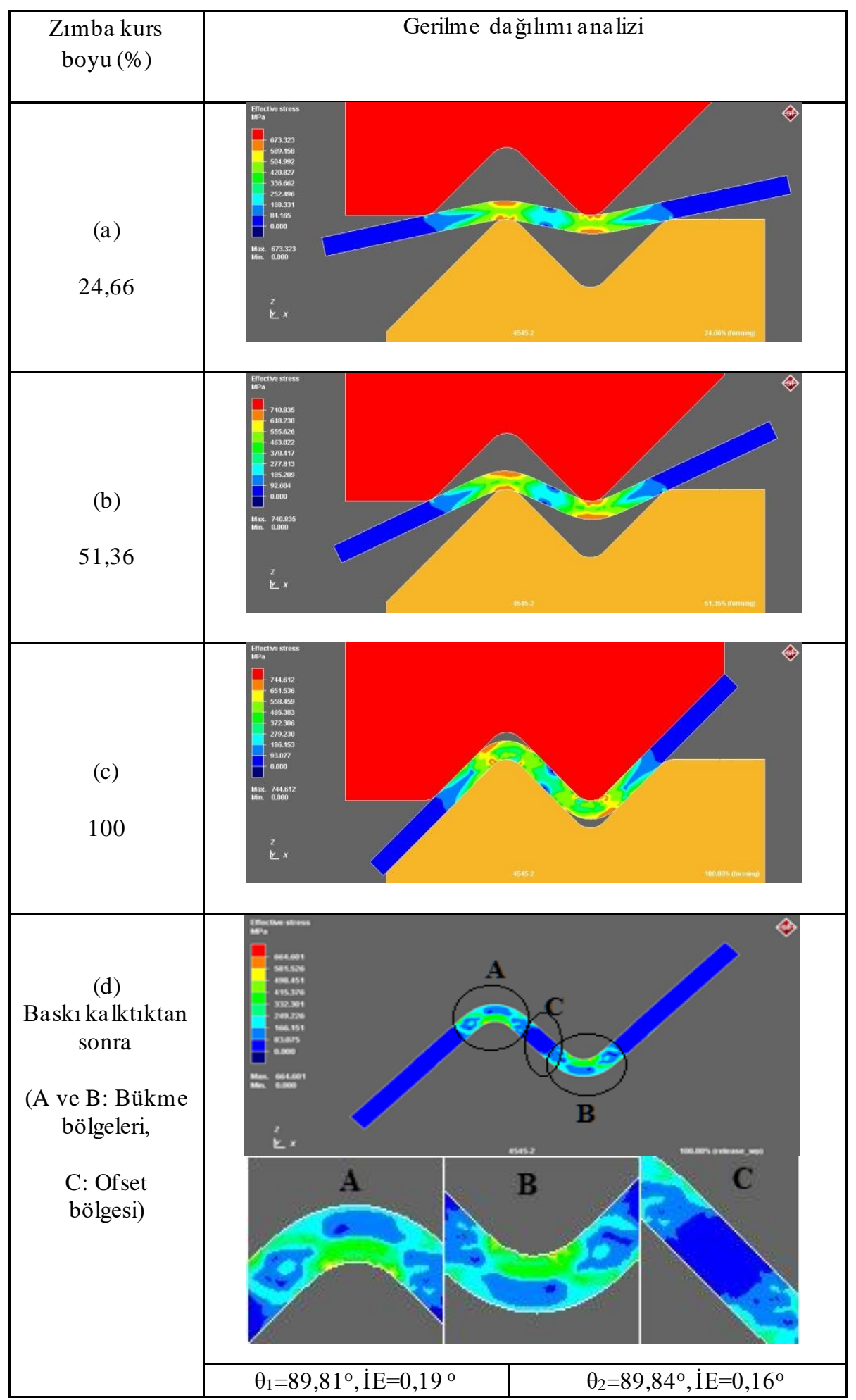

Şekil 5. $45^{\circ}-45^{\circ}$ kalıpla bükme esnasında ve sonrasında oluşan gerilme dağıllımı 


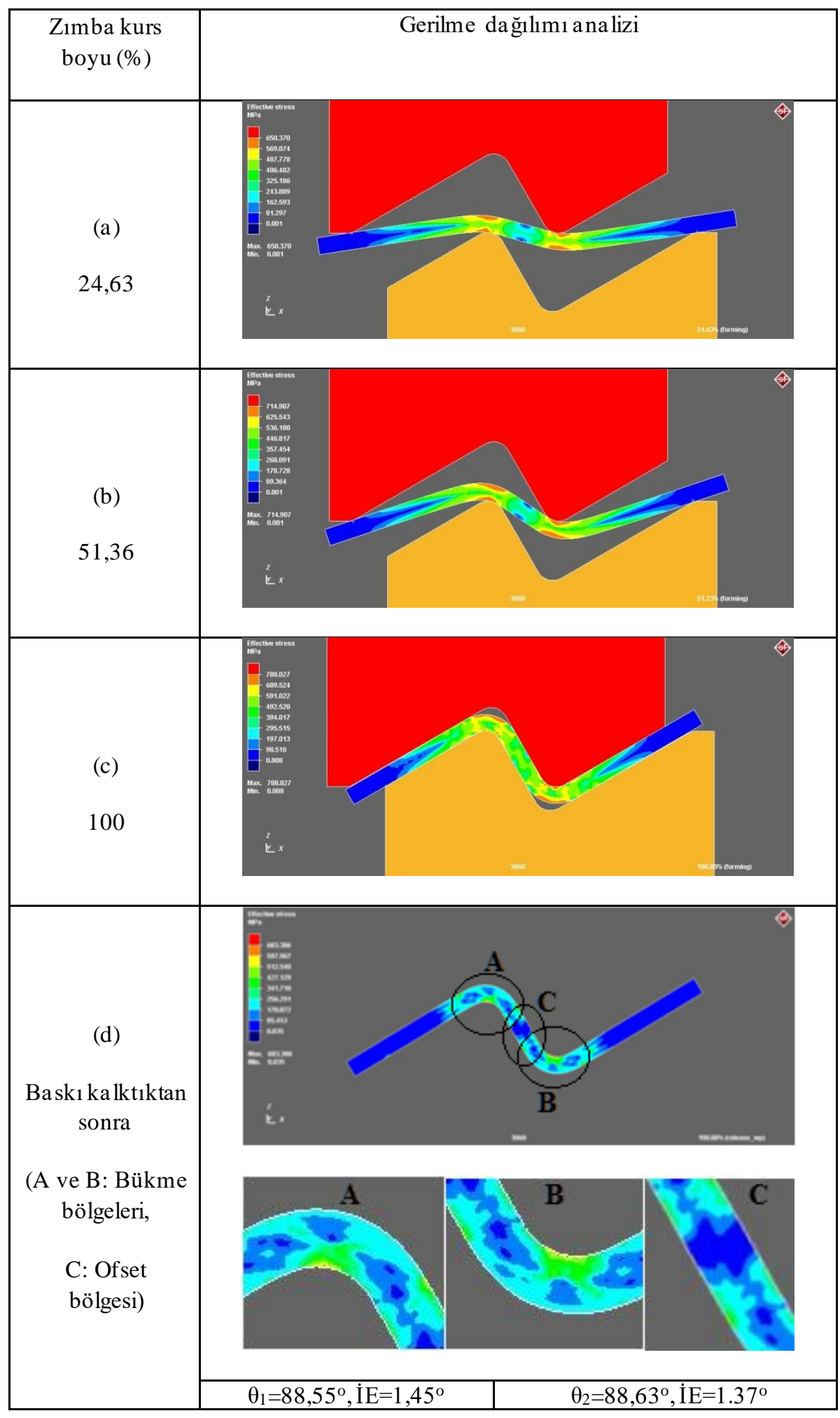

Şekil 6. $30^{\circ}-60^{\circ}$ kalıpla bükme esnasında ve sonrasında oluşan gerilme dağılımı 


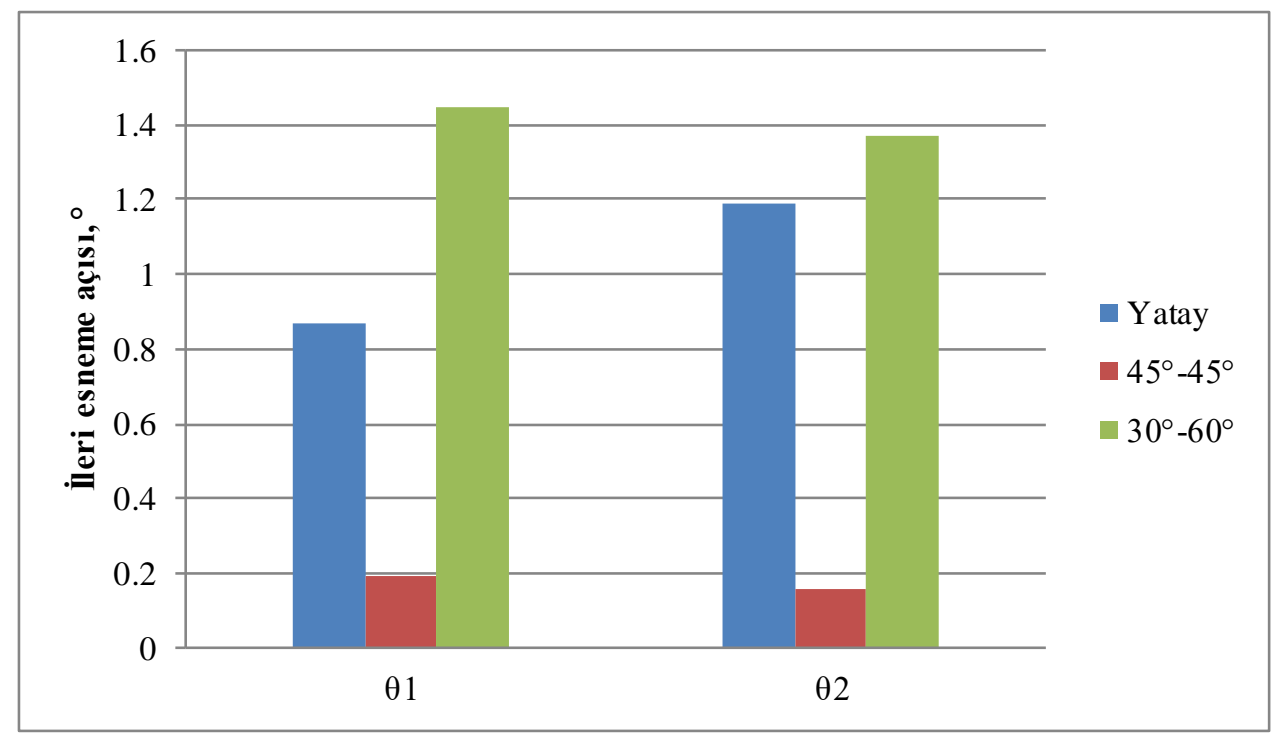

Şekil 7. Bükme sonrası oluşan esneme açıları

\section{SONUCLAR ve ÖNERILER}

$\mathrm{Bu}$ çalışmada, ofset $\mathrm{Z}$ bükme (ofset bükme) işlemi sonrası parçada oluşan geri esnemeye kalıp konumunun etkisi sonlu elemanlar yöntemi kullanılarak araştırılmıştır. Elde edilen sonuçlar şöyle özetlenebilir.

1- En düşük esneme açıs1, $45^{\circ}-45^{\circ}$ konuma sahipkalıplarda, en büyük esneme açısı ise $30^{\circ}-60^{\circ}$ kalıplarda elde edilmiştir.

2- Yatay konuma sahip kalıplarla elde edilen numunelerde önemli oranda hasar oluşmuştur.

$3-45^{\circ}-45^{\circ}$ ve $30^{\circ}-60^{\circ}$ kalıp konumlarında en büyük gerilmeler bükmebölgelerinin iç kısımlarında, yatay kalıp konumunda ise ofset bölgesine yakın bükme bölgelerinde oluştuğu belirlenmiştir. Bu durum yatay konuma sahip kalıpların $90^{\circ}$ 'lik bükme için uygun olmadığını da göstermiştir.

4- Hem bükme hem de ters bükme bölgelerindeki gerilme değerleri eşit olmadığından geri/ileri esneme miktarları da eşit değil, birbirinde farklıdır. Ayrıca bu durum, V bükme teorisinin ofset bükme işlemi için kullanılamayacağını da göstermiştir.

5- Bu çalışma, malzeme kalınlığı, malzeme genişliği, ofset değeri, bükme açısı ve kalıp yarıçapı parametreleri kullanılarak daha da genişletilebilir.

6- Bu çalışma, farklı malzeme türleri, farklı kalıp açıları, malzeme kalınlığı, malzeme hadde yönü, malzeme genişliği, presleme hızı, baskı tutma süresi vb. farklı parametreler kullanılarak daha da genişletilebilir.

\section{KAYNAKLAR}

[1] R. Teimouri, H. Baseri, B. Rahmani, ve M. Bakhshi-Jooybari, "Modeling and optimization of spring-back in bending process using multiple regression analysis and neural computation," Int. J. Mater. Form., c. 7, s. 2, ss. 167-178, 2014. 
[2] M. A. Farsi ve B. Arezoo, "Bending force and spring-back in V-die-bending of perforated sheetmetal components,” J. Brazilian Soc. Mech. Sci. Eng., c. 33, s. 1, ss. 45-51, 2011.

[3] A. S. Darmawan, A. D. Anggono, ve A. Hamid, "Die design optimization on sheet metal forming with considering the phenomenon of springback to improve product quality," MATEC Web Conf., c. 154, ss. 2-5, 2018.

[4] M. Bakhshi-Jooybari, B. Rahmani, V. Daeezadeh, ve A. Gorji, "The study of spring-back of CK67 steel sheet in V-die and U-die bending processes," Mater. Des., c. 30, s. 7, ss. 2410-2419, 2009.

[5] H. Gürün, O. Çavuşoğlu, U. Çaydaş, C. Özek, ve M. Çelik, "AA2024 Alaşımının V-Bükme İşlemi Sonrasında Geri Esneme Davranışlarının İncelenmesi," Fırat Üniversitesi Mühendislik Bilim. Derg., c. 30, s. 1, ss. 1-8, 2018.

[6] K. Lawanwomg, H. Hamasaki, R. Hino, ve F. Yoshida, "A novel technology to eliminate Ubending springback of high strength steel sheet by using additional bending with counter punch," Procedia Eng., c. 81, s. October, ss. 957-962, 2014.

[7] E. Uslu ve N. Tosun, "Experimental Investigation of Springback of DC Series Steel Sheet in VBending Process," Bayburt Üniversitesi Fen Bilimleri Dergisi, c. 2, s. 2, 2019.

[8] F. Gassara, R. Hambli, T. Bouraoui, F. El Halouani, ve D. Soulat, "Optimization of springback in L-bending process using a coupled Abaqus/Python algorithm," Int. J. Adv. Manuf. Technol., c. 44, s. $1-2$, ss. 61-67, 2009.

[9] İ. Karaağaç, "The evaluation of process parameters on springback in V-bending using the flexforming process,” Mater. Res., c. 20, s. 5, ss. 1291-1299, 2017.

[10] S. A. Akinlabi, O. S. Fatoba, P. M. Mashinini, ve E. T. Akinlabi, "Effect of Bottoming on Material Property during Sheet Forming Process through Finite Element Method," IOP Conf. Ser. Mater. Sci. Eng., c. 328, s. 1, ss. 0-8, 2018.

[11] N. Sen, "Experimental investigation of the formability of ultrahigh-strength sheet material using local heat treatment," Ironmak. Steelmak., c. 0, s. 0, ss. 1-7, 2019.

[12] S. Thipprakmas ve P. Komolruji, "Analysis of bending mechanism and spring-back characteristics in the offset Z-bending process," Int. J. Adv. Manuf. Technol., c. 85, s. 9-12, ss. 25892596, 2016.

[13] S. Thipprakmas ve P. Komolruji, "Design of Process Parameters in Wiping Z-bending Process using Statistical Analysis Technique," Procedia Eng., c. 183, ss. 5-10, 2017.

[14] H. Güler, "Ofset Bükme İşleminde Şekillendirme Hızı ve Malzeme Etkisinin Sayısal Olarak İncelenmesi," Makine Teknolojileri Elektronik Dergisi, 11, ss. 75-83, 2014.

[15] S. Thipprakmas and S. Rojananan, "Investigation of spring-go phenomenon using finite element method," Mater. Des., c. 29, s. 8, ss. 1526-1532, 2008. 